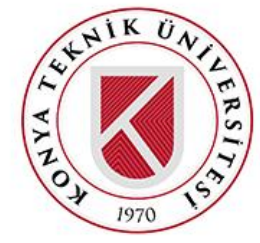

Konya Mühendislik Bilimleri Dergisi, c. 9, Özel Sayı, 54-65, 2021

Konya Journal of Engineering Sciences, v. 9, Special Issue, 54-65, 2021

ISSN: 2667-8055 (Elektronik)

DOI: 10.36306/konjes.979952

\title{
SÜKSİNİK ASİT VARLIĞINDA STRUVİT KRİSTALİZASYONUNUN İNCELENMESİ
}

\author{
${ }^{1}$ Sevgi POLAT ${ }^{(1)}$, 2 Nurseli GÖRENER ${ }^{(1)}$, 3 Perviz SAYAN \\ 1,3 Marmara Üniversitesi, Mühendislik Fakültesi, Kimya Mühendisliği Bölümü, İstanbul, TÜRKIYYE \\ ${ }^{2}$ Gebze Teknik Üniversitesi, Mühendislik Fakültesi, Kimya Mühendisliği Bölümü, Kocaeli, TÜRKIYE \\ ${ }^{1}$ sevgi.polat@marmara.edu.tr, 2ngorener@gtu.edu.tr, ${ }^{3}$ perviz.sayan@marmara.edu.tr
}

(Geliş/Received: 07.08.2021; Kabul/Accepted in Revised Form: 31.10.2021)

\begin{abstract}
ÖZ: Bu çalışmada, saf ortamda ve süksinik asidin katkı maddesi olarak kullanıldığı ortamda üretilen struvit kristallerinin yapısal, morfolojik ve termal özellikleri incelenmiştir. Elde edilen kristaller, XRD, FTIR ve SEM analizleri ile karakterize edilmiş; kristallerin tane boyutu, şekil parametreleri, filtrasyon karakteristiği ve yüzey yükünde meydana gelen değişimler belirlenmiştir. Süksinik asit konsantrasyonunun artmasıyla kristal morfolojisinde, tane boyutunda ve şekil parametrelerinde önemli değişiklikler meydana gelmiştir. Saf ortam ile karşılaştırıldığında kristal morfolojisinde meydana gelen değişimlere bağlı olarak kristallerin filtrasyon karakteristiği de değişmiştir. Katkı konsantrasyonunun artışına bağlı olarak filtrasyon hızında artış, spesifik kek direncinde ise düşüş olduğu belirlenmiştir. Saf ortamda struvit kristallerinin spefisifik kek direnci $4,72 \times 10^{9} \mathrm{~m} / \mathrm{kg}$ iken bu değer 250 ppm katkı konsantrsayonu için $1,03 \times 10^{9} \mathrm{~m} / \mathrm{kg}$ olarak hesaplanmıştır. Elde edilen kristal ürünlerin aynı zamanda termal bozunma davranışları, bozunma kinetiği ve termodinamiği Coats-Redfern modeli kullanılarak incelenmiştir. Mevcut çalışma ile endüstriyel açıdan özellikle atık su arıtıma tesislerinde boru içlerinde tıkanmalara neden olan struvitin morfolojik yapısının süksinik asit ile değiştirilebildiği ve filtrasyon ile ortamdan daha kolay uzaklaştırılabilecek forma dönüştürüldüğü ortaya koyulmuştur. Aynı zamanda struvitin termal bozunma kinetiğinin ve termodinamiğinin belirlenmesi de katkı maddesi olarak kullanılan süksinik asidin etkisini belirlemek açısından önemli katkılar sağlamıştır.
\end{abstract}

Anahtar Kelimeler: Struvit, Kristalizasyon, Morfoloji, Süksinik asit, Coast-Redfern.

\section{Investigation of Struvite Crystallization in the Presence of Succinic Acid}

ABSTRACT: In this study, the structural, morphological and thermal properties of the struvite crystals obtained with and without succinic acid were investigated. The crystals obtained were characterized by XRD, SEM and FTIR analysis; and the variations in their particle size, shape parameters, filtration characteristics and surface charge were determined. The significant changes in the morphology and particle size of the struvite occurred along with the increase in succinic acid concentration. Compared to pure media, the filtration characteristics of the crystals modified depending on the changes in crystal morphology. It was determined that the filtration rate increased, and the specific cake resistance decreased based on the increment of additive concentration. The specific cake resistance was calculated to be $1.03 \times 10^{9} \mathrm{~m} / \mathrm{kg}$ for $250 \mathrm{ppm}$ additive concentration while it was $4.72 \times 10^{9} \mathrm{~m} / \mathrm{kg}$ for pure media. Moreover, the thermal decomposition behavior, kinetics and thermodynamics of the struvite obtained were investigated by Coats-Redfern model. This study has revealed that the morphology of struvite leading to clogging problems in pipes especially in wastewater treatment plants from the industrial point of view could be changed by succinic acid and easily removed from the media. The understanding of thermal 
decomposition kinetics and thermodynamics of struvite has provided important contributions in terms of the determination of additive effects.

Keywords: Struvite, Crystallization, Morphology, Succinic acid, Coast-Redfern.

\section{GİRIŞ (INTRODUCTION)}

Yapısında yüksek oranda fosfat ve amonyak bulunduran struvit $\left(\mathrm{MgNH}_{4} \mathrm{PO}_{4} .6 \mathrm{H}_{2} \mathrm{O}\right)$ kristalleri genellikle kararlı ortorombik bir yapıya sahiptir (Tansel ve diğ., 2018). Yapısında ağırlıkça \%9.8 magnezyum, \%7.3 amonyum, \%38.8 fosfat ve \%44.1 su ve organik maddeler içermektedir (Perwitasari ve diğ., 2017). Sıcaklık, pH, iyonlar arası etkileşim ve kalma süresine bağlı olarak iyonlaşma derecelerinde meydana gelen değişiklikler, nevberit $\left(\mathrm{Mg}\left(\mathrm{PO}_{3} \mathrm{OH}\right) .3 \mathrm{H}_{2} \mathrm{O}\right)$, bobierit $\left(\mathrm{Mg}_{3}\left(\mathrm{PO}_{4}\right)_{2} .8 \mathrm{H}_{2} \mathrm{O}\right)$ ve ditmarit $\left(\mathrm{MgNH}_{4} \mathrm{PO}_{4} \mathrm{H}_{2} \mathrm{O}\right)$ gibi farklı morfolojik yapıda kristallerin oluşmasına sebep olmaktadır (Tansel ve diğ., 2018). Polimorfik yapısı ile dikkat çeken bir mineral olan struvit, içeriğindeki yüksek fosfat oranı ile endüstriyel alanda yavaş salınımlı gübre olarak gelecek vaat eden bir kaynak olarak görülse de özellikle atık su arıtma tesislerinde yarattığı ciddi tıkanıklık problemleri ile çözülmesi gereken bir sorun haline gelmiştir (Yan ve Shih, 2016). Sudaki düşük çözünürlüğünden dolayı struvit, özellikle nötr ve alkali ortamlarda kolaylıkla çökme eğilimi göstermektedir (Harrison ve dĭ̆., 2011). Bununla birlikte, karbondioksit çıkışına bağlı olarak sistemde görülen $\mathrm{pH}$ artışı ve proses içinde enerji artışından kaynaklı yüksek türbülans atık su arıtma tesislerinde karşılaşılan struvit kaynaklı problemlerin temel sebeplerindendir (Fattah, 2012; Neethling ve Benisch, 2004). Bu nedenle, yüksek türbülansın görüldüğü pompalar, vanalar, boru dirsekleri ve türbinli karıştırıcılar struvit oluşumu için en elverişli yerlerdir. Ayrıca 1sı değiştiricilerin, boruların ve santrifüjlerin yüzeylerinde de biriken struvitin yarattığı tıkanıklık probleminin zamanında ve kısa sürede giderilememesi, sistemde uzun süreli duruşlara ve dolaylı olarak işletme, yatırım ve bakım masraflarında artışa sebebiyet vererek ekonomik açıdan da sorun oluşturabilmektedir (Neethling ve Benisch, 2004). Bu sebeplere dayanarak struvit kristalizasyonun anlaşılması, endüstriyel alanda struvit oluşumunun kontrol edilmesi ve problemlerin giderilmesi önemli bir konu haline gelmiştir.

Struvit kristalizasyonunun nükleasyon ve kristal büyümesi ile temel olarak iki aşamada gerçekleştiği ve kristalizasyon mekanizmasının $\mathrm{pH}$, sıcaklık, aşırı doygunluk, karıştırma hızı ve katkı maddelerinin varlığı gibi pek çok faktörlerden etkilendiği bilinmektedir (Neethling ve Benisch, 2004; Yan ve Shih, 2016). Daha önce yapılan çalışmalarda, katkı maddelerinin kristalizasyon mekanizması üzerinde önemli etkileri olduğu, nükleasyonu başlatıcı ya da kristallerin aktif büyüme bölgelerine etki ederek nükleasyonu inhibe edici etkisi olduğu ortaya konmuştur (Wada ve diğ., 2001, Akyol ve Öner, 2014). Literatürde de organik ve inorganik katkı maddelerinin struvit kristalizasyonuna etkisinin incelendiği çalışmalar mevcuttur. Zhang ve arkadaşları, sitrik asidin ve humik asidin struvit kristal oluşumu ve kristal büyümesi üzerine inhibe edici etkilerinin olduğunu, glikozun ise yüksek konsantrasyonlarda struvit oluşumuna katkı sağladığını ortaya koymuşlardır (Zhang ve diğ., 2016). Song ve arkadaşlarının yaptığı çalışmada, sitrik ve asetik asidin struvit oluşumu üzerine etkileri incelenmiş olup özellikle sitrik asidin kristal morfolojisini değiştirdiği ortaya konmuştur (Song ve diğ. 2014). Polat ve arkadaşları, asetik, oksalik ve trikarballik asidin struvit kristalizasyonuna etkisini incelemiş özellikle yüksek oksalik asit konsantrasyonunda kristallerin boyutlarında önemli bir artış olduğunu belirlemişlerdir (Polat ve diğ. 2021). Wei ve arkadaşları, aljinik asidin struvit üzerindeki adsorpsiyon mekanizmasını incelemiş ve bu asidin kristalizasyon mekanizması üzerine inhibe edici etkisini ortaya koymuşlardır (Wei ve di ̆., 2019). Bu çalışmada ise endüstriyel alanda struvit kaynaklı problemlerin giderilmesine yönelik olarak karboksilik bir asit olan süksinik asidin struvitin kristal yapısına, morfolojisine, şekil parametrelerine ve filtrasyon karakteristiğine olan etkileri incelenmiştir. Ayrıca, Coats-Redfern modeli kullanılarak kinetik ve termodinamik analiz yapılmıştır. 


\section{MATERYAL ve YÖNTEM (MATERIALS and METHOD)}

Struvit kristallerinin sentezi, Merck firmasından temin edilen ve analitik saflıkta magnezyum klorür hekzahidrat $\left(\mathrm{MgCl}_{2} .6 \mathrm{H}_{2} \mathrm{O}\right)$ ve amonyum dihidrojen fosfat $\left(\mathrm{NH}_{4} \mathrm{H}_{2} \mathrm{PO}_{4}\right)$ kullanılarak kesikli bir sistemde, 1L kapasiteli çift ceketli bir kristalizörde gerçekleştirilmiştir. Deney düzeneği Şekil 1'de verilmiştir.

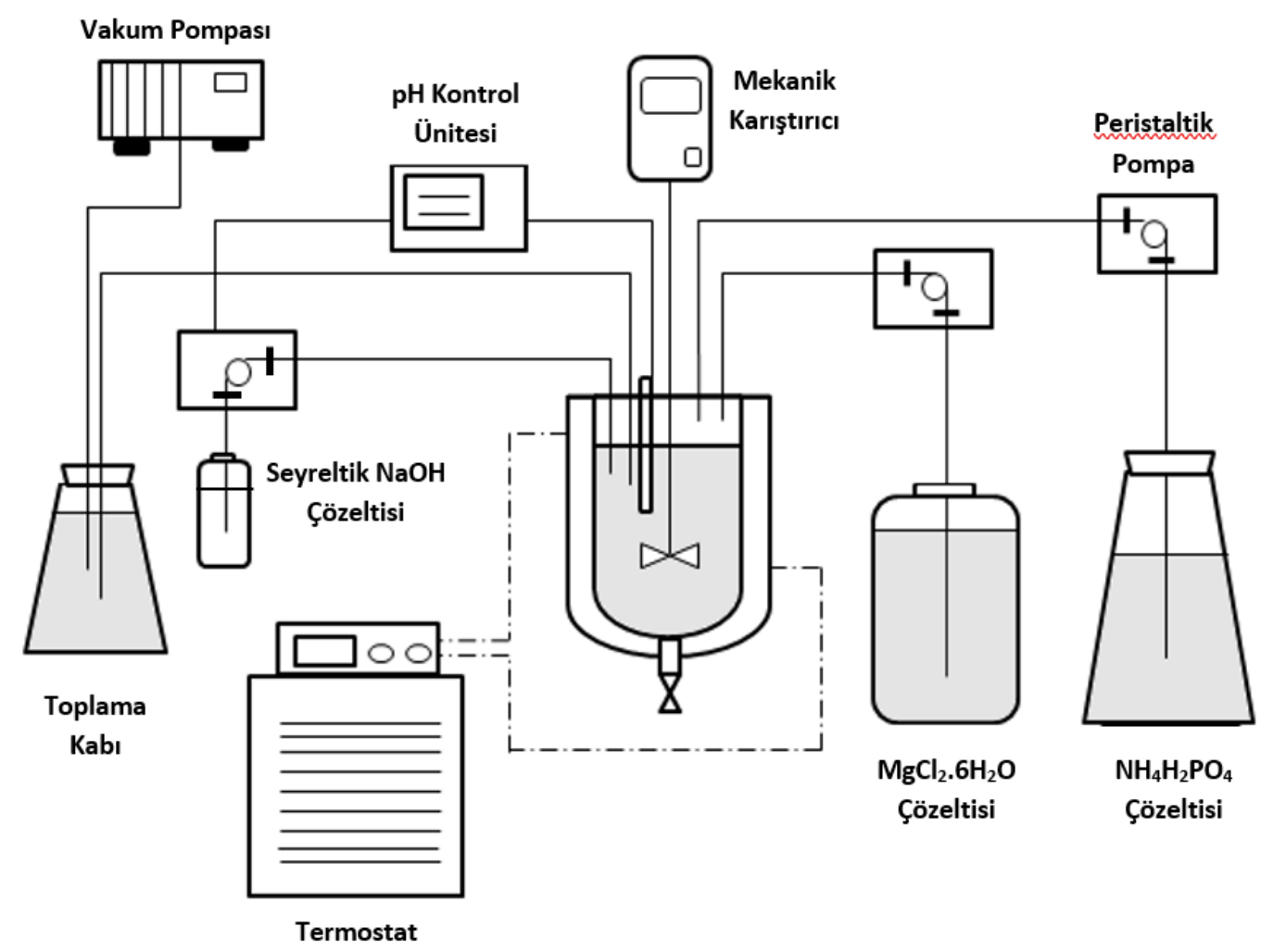

Şekil 1. Deney düzeneği.

Figure 1. Experimental setup

1,0 $\mathrm{M} \mathrm{MgCl}_{2} .6 \mathrm{H}_{2} \mathrm{O}$ ve 1,0 $\mathrm{M} \mathrm{NH}_{4} \mathrm{H}_{2} \mathrm{PO}_{4}$ çözeltilerinin kristalizöre beslenmesi peristaltik pompalar aracılığıyla ile yapılmıştır. Deneyler $40{ }^{\circ} \mathrm{C}, 8,0 \mathrm{pH}$ ve $500 \mathrm{rpm}$ karıştırma hızında gerçekleştirilmiştir. Kristalizör içi sıcaklık termostat yardımıyla sabit tutulmuştur. Karıştırma işlemi üç kanatlı bir karıştırıcı tarafından sağlanmış ve karıştırma hızı devri mekanik olarak ayarlanabilen bir motor tarafından ayarlanmıştır. Kristalizör içerisindeki pH üçüncü bir kanaldan beslenen seyreltik NaOH çözeltisi yardımı ile sabit tutulmuş ve pH kontrol ünitesi ile kontrol edilmiştir. Deneyler öncelikle saf ortamda daha sonra katkı maddesi olarak kullanılan süksinik asit varlığında gerçekleştirilmiştir. 100 ve 250 ppm olmak üzere iki farklı süksinik asit konsantrasyonunda çalışılmıştır. Kristalizasyon işlemi sonunda süspansiyon 0,45 $\mu \mathrm{m}$ selüloz nitrat filtre kâğıdı ile vakum altında filtrelenmiş, katı ürün distile su ile yıkanarak oda sıcaklığında kurutulmuştur. Elde edilen nihai ürünün yapısal, morfolojik ve termal karakterizasyonu XRD, FTIR, SEM, TG/DTG, tane boyutu ve zeta potansiyeli analiz yöntemleri kullanılarak gerçekleştirilmiştir. Ayrıca, kristalizör içeriğini temsil eden karakteristik süspansiyonun filtrasyon hızı ölçümleri yapılmıştır. Filtrasyon deneyleri 110 mbar sabit basınç altında gerçekleştirilmiş ve elde filtrasyon verileri Darcy yasasına (Holdich, 1990) göre değerlendirilerek struvit kristallerin filtrasyon karakteristiği belirlenmiştir. Buna göre, toplanan filtrat hacmi ile zaman arasındaki ilişki aşağıda verilen eşitlikle ifade edilmiştir.

$\frac{d t}{d V}=K_{p} V+B$ 
$\mathrm{dt} / \mathrm{dV}$ ile $\mathrm{V}$ arasında çizilecek grafik lineer bir doğru verecek, bu doğrunun eğiminden ve kesim noktasından sırasıyla Kp ve B sabitleri bulunabilecektir. Kp ve B sabitleri aşağıda eşitliklerle ifade edilmiştir.

$$
\begin{aligned}
& K_{p}=\frac{c \alpha \mu}{S^{2}(-\Delta P)} \\
& B=\frac{R_{m} \mu}{S(-\Delta P)}
\end{aligned}
$$

Eşitliklerde geçen, c $\left(\mathrm{kg} / \mathrm{m}^{3}\right)$ süspansiyon konsantrasyonu, $\mu(\mathrm{kg} / \mathrm{m} . \mathrm{s})$ viskozite, $\mathrm{S}\left(\mathrm{m}^{2}\right)$, filtre yüzey alanı, $\Delta \mathrm{P}\left(\mathrm{kg} / \mathrm{m}^{2}\right)$, filtrasyon işleminin yürütüldüğü basınç, $\alpha(\mathrm{m} / \mathrm{kg})$, ortalama spesifik kek direnci, Rm $(1 / \mathrm{m})$, filtre ortamı direncini göstermektedir. Eşitlik 2 ve 3 kullanılarak ortalama spesifik kek direnci ve filtre ortamı direnci hesaplanabilmektedir.

\section{BULGULAR (RESULTS)}

\section{XRD ve FTIR Analizi (XRD and FTIR Analysis)}

Saf ortamda ve süksinik asit varlı̆̆ında elde edilen kristallerin yapısal özellikleri XRD analiz yöntemiyle incelenmiş ve sonuçlar Şekil 2'de verilmiştir.

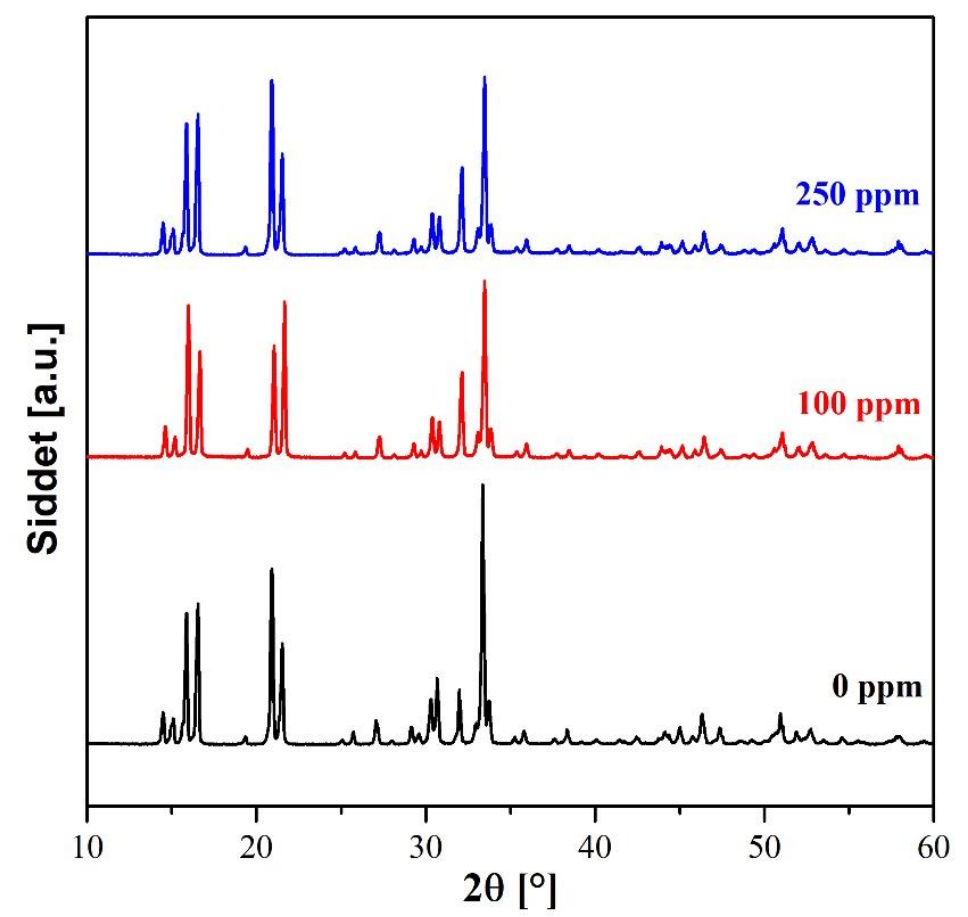

Şekil 2. Saf ortamda ve süksinik asit varlı̆̆ında elde edilen struvit kristallerinin XRD sonuçları.

Figure 2. XRD results for the struvite crystals obtained with and without the succinic acid.

Saf ortamda elde edilen sonuçlara benzer şekilde, her iki süksinik asit konsantrasyonunda da elde edilen kristaller struvit yapısında olup farklı bir faz oluşumuna rastlanmamıştır. Saf ortamda üretilen kristaller için elde edilen XRD profili incelendiğinde, struvit kristal yapısını karakterize eden $2 \theta$ değerleri $14.5^{\circ}(101), 20.9^{\circ}(111), 27.1^{\circ}(103), 33.6^{\circ}(022)$ ve $45.9^{\circ}$ (303) olarak belirlenmiştir. Bu sonuç, saf ortamda üretilen numunenin ortorombik yapıdaki struvit kristalleri olduğunu göstermiştir. MAUD programı kullanilarak yapılan hesaplamalar ile kristal yapiya ait parametreler $a=6.960 \AA, b=6.141 \AA, c=11.236 \AA$ olarak hesaplanmıştır. 
XRD analizine paralel olarak hem kristal yapısını belirlemek hem de saf ve süksinik asit varlığında elde edilen numunelerin fonksiyonel gruplarını tespit etmek amacıyla FTIR analizi yapılmış ve sonuçlar Şekil 3'de verilmiştir.

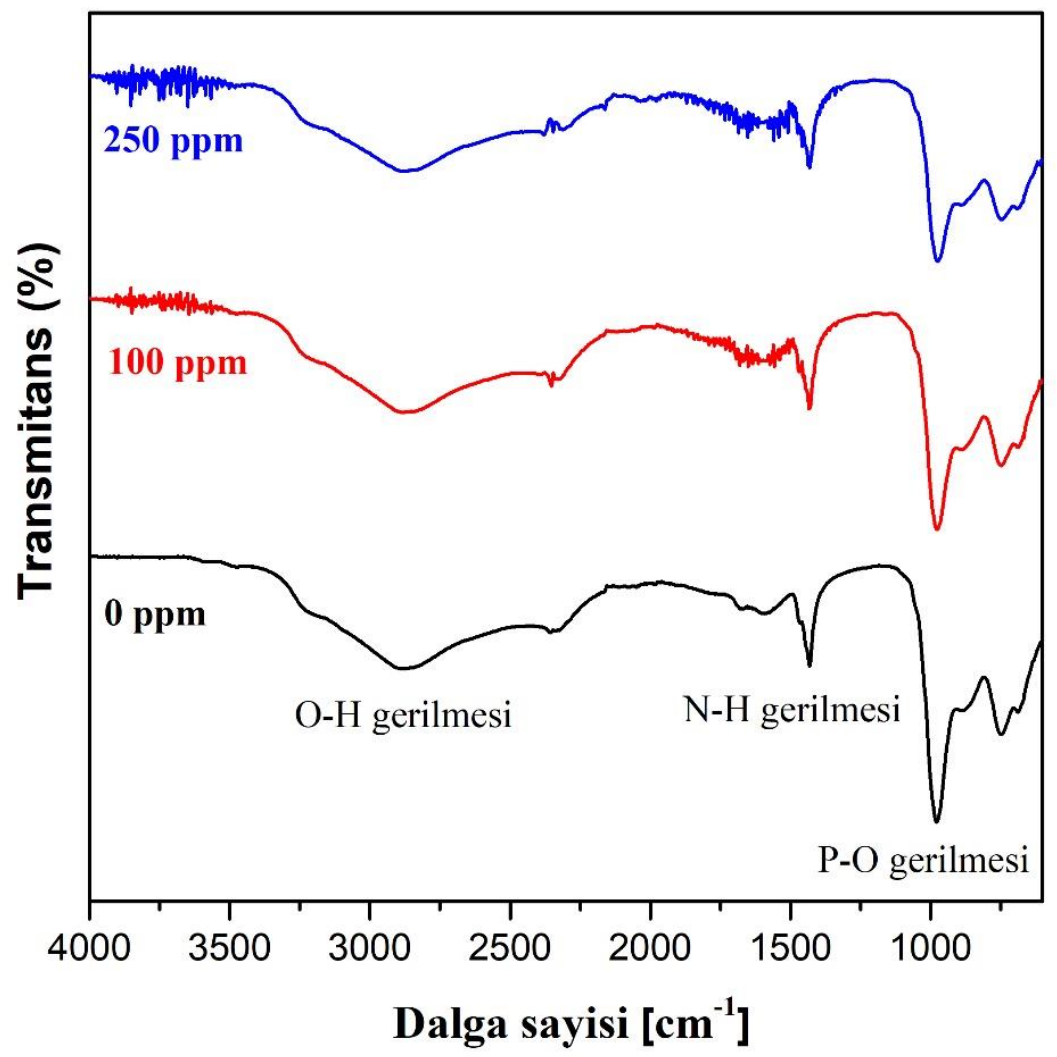

Şekil 3. Saf ortamda ve süksinik asit varlığında elde edilen struvit kristallerinin FTIR sonuçları.

Figure 3. FTIR results for the struvite crystals obtained with and without the succinic acid.

Saf ortamda üretilen kristaller XRD analizinde de belirtildiği üzere struvit yapısındadır. 3000-3500 $\mathrm{cm}^{-1}$ bant aralığında görülen pik kristal yapısında bulunan suyun varlığını gösteren $\mathrm{O}-\mathrm{H}$ gerilmesini, $\sim 2980 \mathrm{~cm}^{-1}$ ve $\sim 980 \mathrm{~cm}^{-1}$ de görülen pikler ise $\mathrm{N}-\mathrm{H}$ ve P-O gerilmesini göstermektedir. Ayrıca, literatürde verilen sonuçlar ile de uyumlu olarak $\sim 1430 \mathrm{~cm}^{-1}, \sim 980 \mathrm{~cm}^{-1}$ ve $\sim 760 \mathrm{~cm}^{-1}$ dalga boylarında tespit edilen pikler de struvit yapısını karakterize etmektedir (Foletto ve diğ., 2013). FTIR ve XRD sonuçları birbirini desteklemektedir.

Süksinik asit varlığında elde edilen struvit kristalleri için FTIR spektrumları incelendiğinde saf ortamdakine benzer fonksiyonel gruplar tespit edilmiştir. Süksinik asidi karakterize eden farklı bir pik görülmemesine rağmen, pik şiddetlerinin değiştiği görülmüştür. Bu sonuç, katkı maddesinin struvitin yüzeyine fiziksel olarak bağlandığını göstermektedir.

\section{Zeta Potansiyeli Analizi (Zeta Potential Analysis)}

Bu çalışmada, süksinik asidin struvit kristallerin yüzey yük değerlerine olan etkisi ve katkı maddesinin adsorplanma potansiyelinin tespiti zeta potansiyelin ölçülmesi ile belirlenmiştir. Struvit kristalleri için yüzey yükünün alkali ortamda negatif değere sahip olduğu daha önce yapılan çalışmalar ile ortaya konmuştur (Bouropoulos ve Koutsoukos, 2000; Le Corre ve diğ., 2007). Bu çalışmada, zeta potensiyeli değeri $-15.1 \pm 1.3 \mathrm{mV}$ ile $-26.2 \pm 1.7 \mathrm{mV}$ aralığında değişim göstermektedir (Şekil 4). 


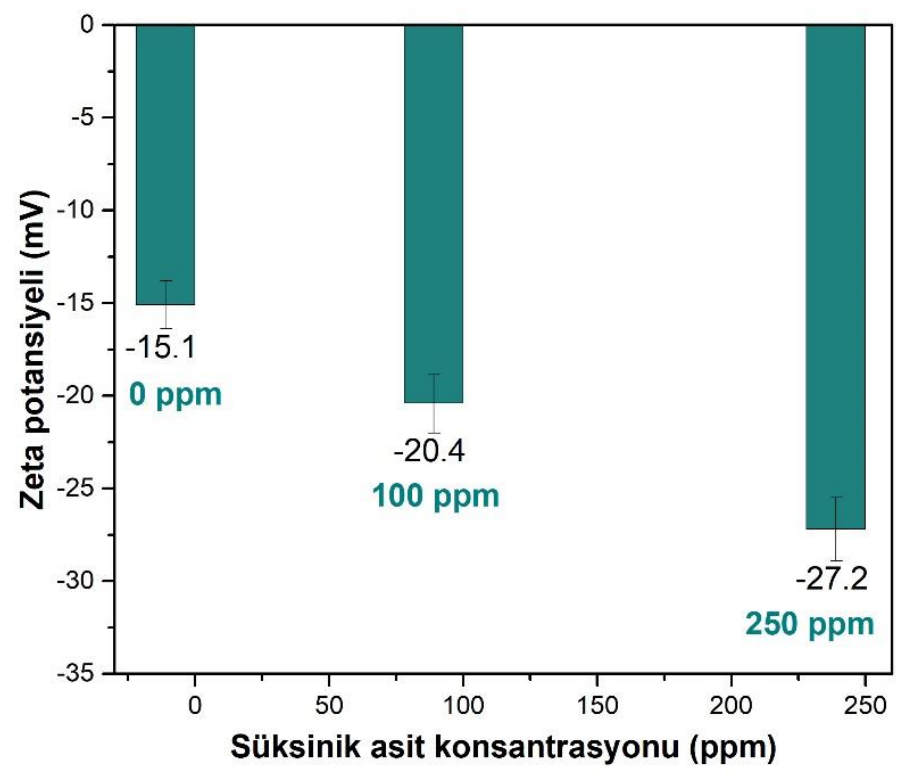

Şekil 4. Saf ortamda ve süksinik asit varlığında elde edilen struvit kristallerinin zeta potansiyeli analiz sonuçları.

Figure 4. Zeta potential analysis results for the struvite crystals obtained with and without the succinic acid.

Saf ortamda üretilen struvit kristalleri için zeta potansiyeli değeri literatür ile de uyumlu olarak $-15.1 \pm 1.3 \mathrm{mV}$ olarak ölçülmüştür (Wei ve diğ., 2019). Şekil 4'den de görüldüğü üzere süksinik asit konsantrasyonun artmasıyla birlikte ölçülen zeta potansiyel değeri izoelektrik noktadan uzaklaşarak daha negatif değere ulaşmıştır. Zeta potansiyeli sonuçları; FTIR analiz sonuçlarıyla birlikte değerlendirildiğinde kullanılan katkı maddesinin, struvitin yüzeyine zayıf Van der Waals kuvvetleriyle bağlandığını göstermektedir.

\subsection{SEM Analizi (SEM Analysis)}

Saf ortamda ve süksinik asit varlığında elde edilen struvit kristallerinin SEM fotoğrafları Şekil 5' de verilmiştir. Saf ortamda elde edilen struvit kristalleri literatürde de belirtildiği gibi çubuk formunda olup, birbirleri üzerinde büyüme eğilimi göstermektedir (Le Corre ve diğ., 2005). Oluşan kristaller sağlam yapıda olup ortamın hidrodinamik koşulları etkisiyle kırılma veya dağılıma eğilimi göstermemektedir. Kristallerin ortalama tane boyutları 17,6 $\mu \mathrm{m}^{\prime}$ dir. 

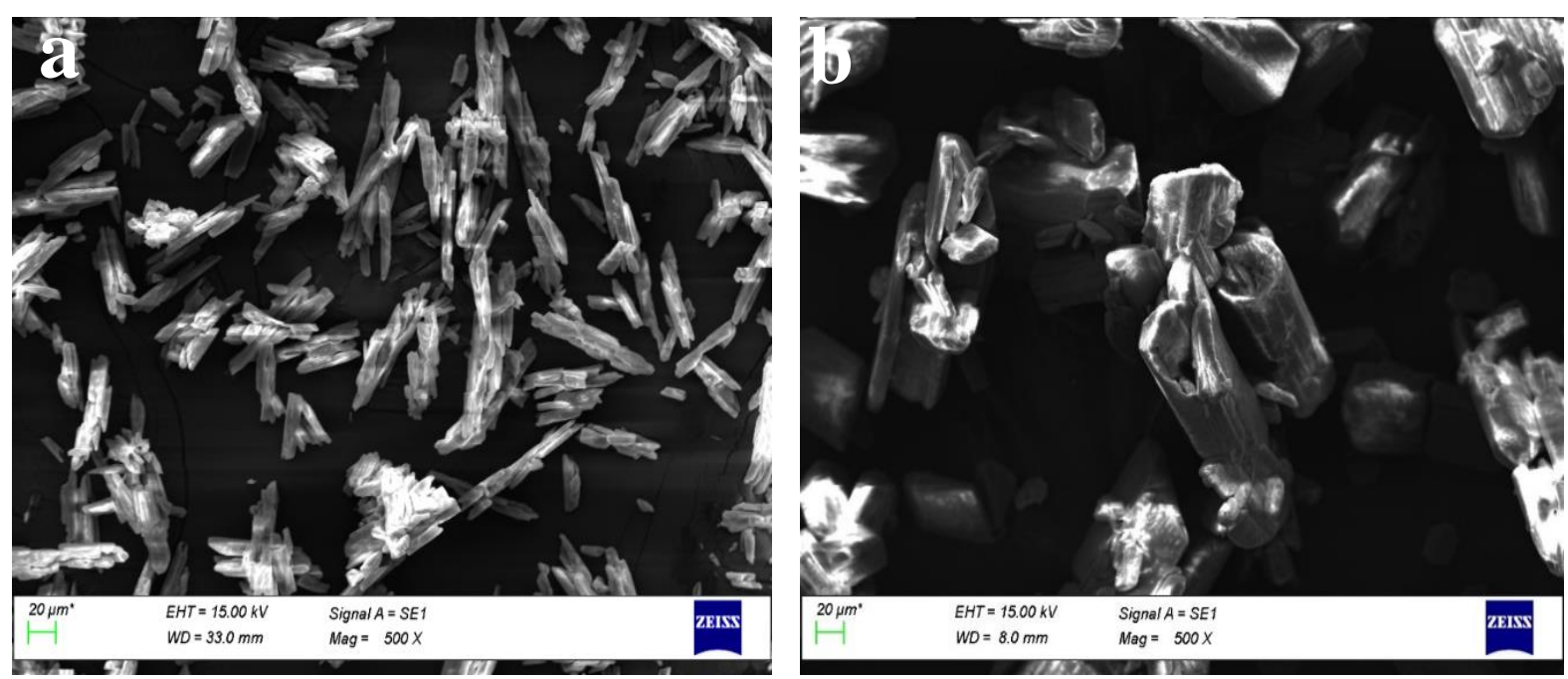

Şekil 5. Saf ortamda (a) ve süksinik asit (b) varlı̆̆ında elde edilen struvit kristallerinin SEM görüntüleri. Figure 5. SEM images of the struvite crystals obtained without (a) and with (b) the succinic acid.

SEM analizine ek olarak kristal morfolojisinde meydana gelen değişimi daha iyi açıklayabilmek için kristal şekil parametreleri yani uzama, küresellik ve aspect (en/boy) oranları Malvern Morphologi G3 cihazı kullanılarak belirlenmiş ve sonuçlar Şekil $6^{\prime}$ da verilmiştir. Saf ortam ile karşılaştırıldığında kristallerin aspect oranlarında ortalama $\% 40$ 'llk bir artış meydana gelmiştir. Süksinik asit konsantrasyonun artmasıyla birlikte kristallerinin küresellik faktörü 0,421'den 0,632'ye çıarken, uzama faktörü $0,637^{\prime}$ den $0,487^{\prime}$ e düşmüştür. Struvitin morfolojisinde ve şekil parametrelerinde meydana gelen bu değişim, süksinik asidin kristal yüzeylerine elektrostatik etkileşim ve seçimli yüzey adsorbsiyon mekanizması ile bağlanmasından kaynaklanmaktadır.

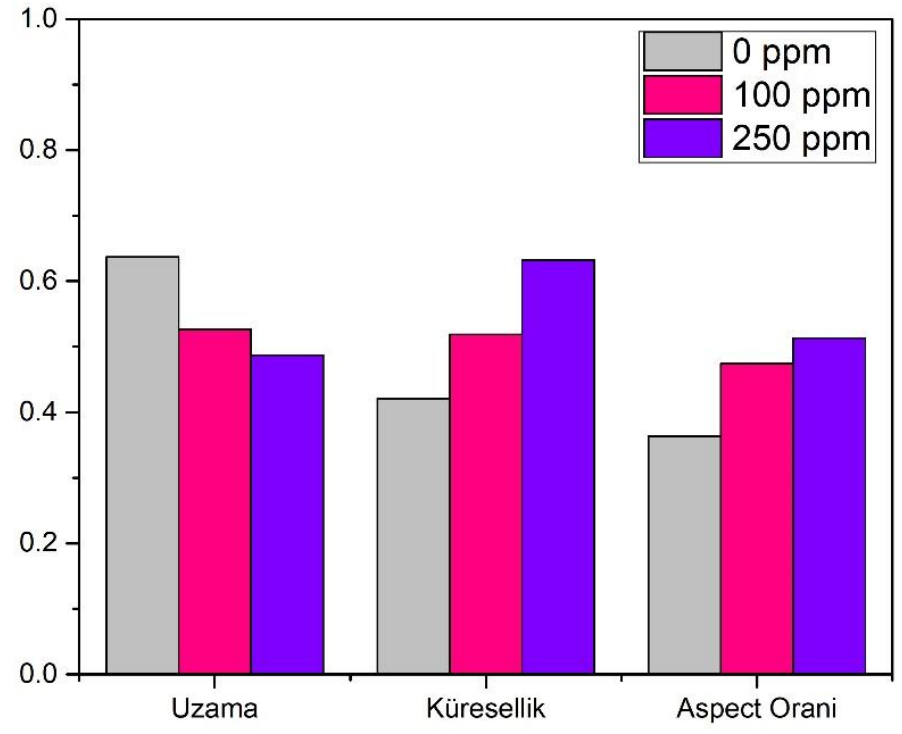

Şekil 6. Farklı süksinik asit konsantrasyonlarında struvitin şekil parametrelerinin değişimi.

Figure 6. The variation of shape parameters as a function of succinic acid concentration.

\section{Filtrasyon Analizi (Filtration Analysis)}

Süksinik asidin struvitin filtrasyon karakteristiği üzerine olan etkisini belirlemek için filtrasyon huzları ölçülmüş, elde edilen veriler Darcy yasasına (Holdich, 1990) göre değerlendirilerek spesifik kek direnci değerleri hesaplanmıştır. Sonuçlar Çizelge 1'de verilmiştir. Saf ortam ile karşılaştırıldığında, süksinik asit 
varlığında elde edilen kristallerin filtrasyon hızlarında artış gözlemlenirken spesifik kek direnci değerlerinde düşme gözlemlenmiştir. Filtrasyon karakteristiğinde meydana gelen bu iyileşme, kristalizasyon ortamına eklenen süksinik asidin kristal morfolojisi ve tane boyutunda meydana getirdiği değişimden kaynaklanmaktadır.

Çizelge 1. Filtrasyon analiz sonuçları.

Table 1. Filtration analysis results

\begin{tabular}{ccc}
\hline Konsantrasyon $(\mathbf{p p m})$ & Spesifik kek direnci $(\mathbf{m} / \mathbf{k g})$ & Filtrasyon hiz1 (ms) \\
\hline 0 & $4,72 \times 10^{9}$ & $0,36 \times 10^{-6}$ \\
100 & $2,29 \times 10^{9}$ & $1,11 \times 10^{-6}$ \\
250 & $1,03 \times 10^{9}$ & $1,26 \times 10^{-6}$ \\
\hline
\end{tabular}

\section{Termogravimetrik Analiz (Thermogravimetric Analysis)}

$\mathrm{Bu}$ çalışmada, saf ortamda ve 250 ppm süksinik asit varlığında elde edilen kristallerinin termal bozunma davranışı $10{ }^{\circ} \mathrm{C} /$ dak ısıtma hızında azot atmosferinde gerçekleştirilen termal analiz işlemi ile incelenmiştir. TG/DTG eğrileri Şekil 7'de verilmiştir.

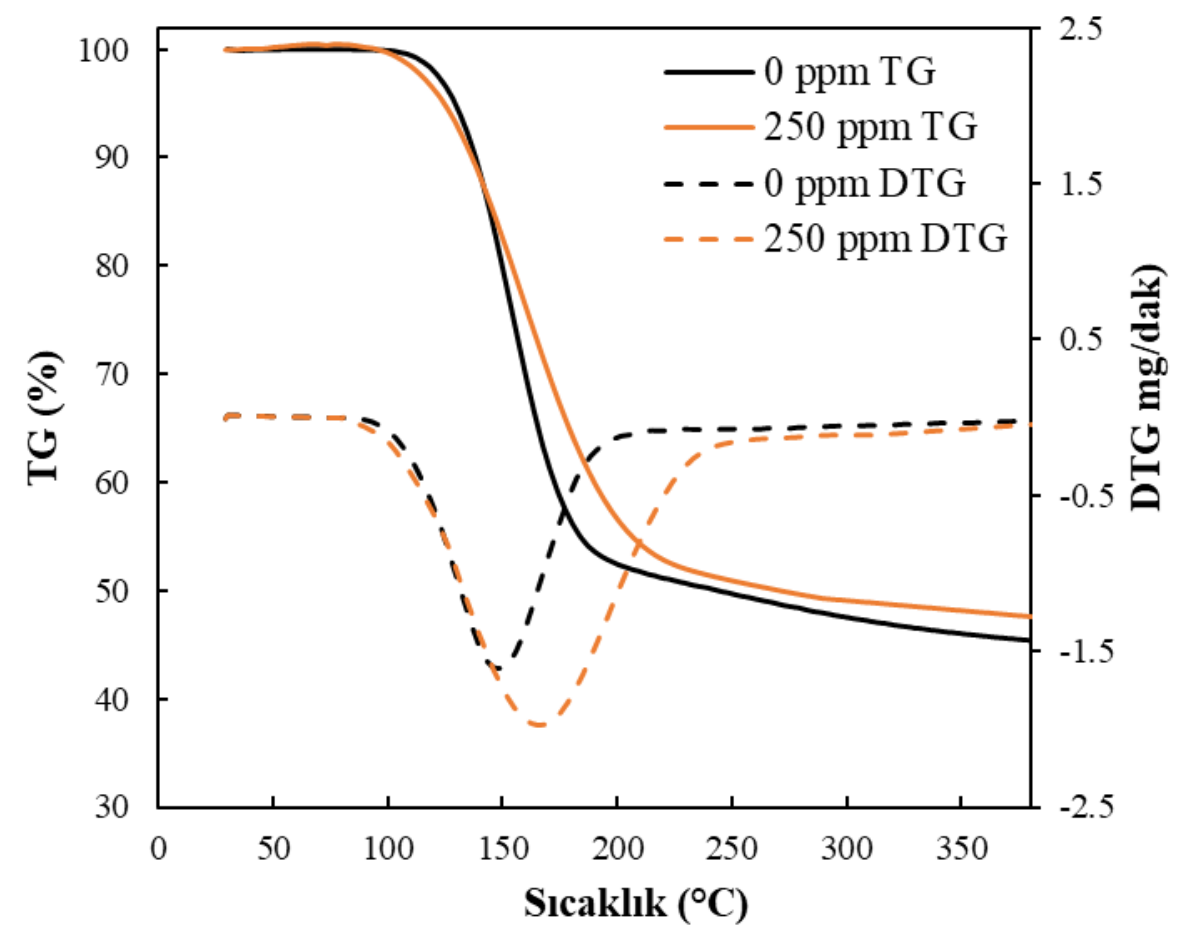

Şekil 7. Saf ortamda ve süksinik asit varlı̆̆ında elde edilen struvit kristallerinin TG/DTG eğrisi.

Figure 7. TG/DTG curves of the struvite crystals obtained with and without the succinic acid.

Bu sonuçlar incelendiğinde hem saf ortamda hem de 250 ppm süksinik asit varlığında elde edilen struvit kristallerinin termal bozunma sürecinin literatür ile uyumlu olarak tek adımda gerçekleştiği görülmüştür. Meydan gelen kütle kaybı su ve amonyağın eş zamanlı olarak bozunmasından kaynaklanmaktadır (Zhou ve diğ., 2015). 


\subsection{Kinetik ve Termodinamik Analiz (Kinetic and Thermodynamic Analysis)}

Saf ortamda ve süksinik asit varlığında elde edilen struvit kristallerinin termal bozunma kinetiği ve termodinamiği Coast-Redfern (Coats ve Redfern, 1964) modeli kullanılarak incelenmiştir. Arrhenius eşitliğinden türetilen Coats-Redfern modeli, aktivasyon enerjisi, reaksiyon mertebesi ve frekans faktörünün birlikte hesaplanmasına olanak sağlamakta olup eşitlikler 4 ve 5 'de verilmiştir.

$\mathrm{n} \neq 1$ için;

$$
\ln \left[\frac{1-(1-\alpha)^{1-n}}{(1-n) T^{2}}\right]=\ln \frac{A R}{\beta E}-\frac{E}{R T}
$$

Farklı n değeri için $1 / \mathrm{T}$ ye karşılık $\ln \left[\frac{1-(1-\alpha)^{1-n}}{(1-n) T^{2}}\right]$ grafiğe çizildiğinde grafiğin eğiminden aktivasyon enerjisi, $E$, kesiminde ise $\ln \left[\frac{A R}{\beta E}\right]$ değeri ile frekans faktörü hesaplanır.

$\mathrm{n}=1$ için;

$\ln \left[-\ln \frac{1-\alpha}{T^{2}}\right]=\ln \frac{A R}{\beta E}-\frac{E}{R T}$

$1 / T$ ye karşılık $\ln \left[-\ln \frac{1-\alpha}{T^{2}}\right]$ grafiğe çizildiğinde grafiğin eğiminden $-E / R$ değeri kesiminden ise $\ln \left[\frac{A R}{\beta E}\right]$ değeri hesaplanır.

Kinetik analize ek olarak termodinamik hesaplamalar için entalpi değişimi $(\Delta H)$, Gibbs serbest entalpi değişimi $(\Delta G)$ ve entropi değişimi $(\Delta S)$ Eşiklik 6-8 kullanılarak hesaplanmıştır (Eyring, 1935; Evans ve Polanyi, 1935).

$\Delta H=E-R T_{\max }$

$\Delta G=E+R T_{\max } \ln \left(\frac{K_{B} T_{\max }}{h A}\right)$

$\Delta S=\frac{\Delta H-T \Delta G}{T_{\max }}$

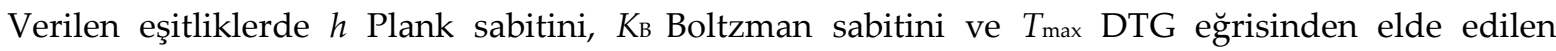
maksimum pik sıcaklığını ifade etmektedir.

İlk olarak struvit kristallerinin termal bozunma sürecindeki reaksiyon derecesi belirlenmiş ve grafikler Şekil 8’de verilmiştir. 

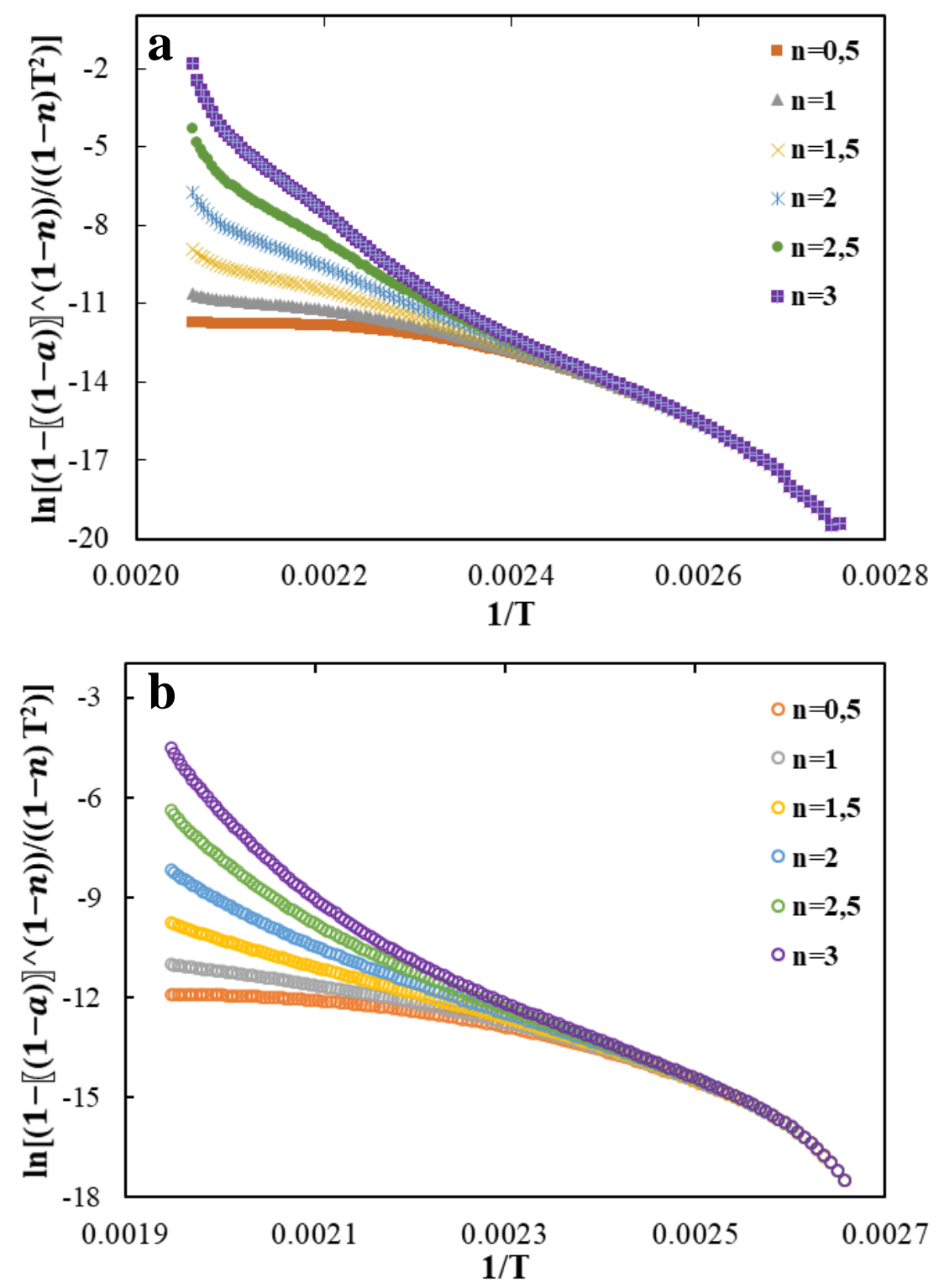

Şekil 8. Saf ortamda (a) ve süksinik asit (b) varlığında elde edilen struvit kristalleri için $\ln \left(\frac{1-(1-\alpha)^{1-n}}{(1-n) \mathrm{T}^{2}}\right)-1 /$ T grafiği.

Figure 8. Plos of $\ln \left[\frac{1-(1-\alpha)^{1-n}}{(1-n) T^{2}}\right]$ to $1 / T$ for the struvite crystals obtained with and without the succinic acid.

Her iki ortam için de reaksiyon mertebeleri farklı n değerleri için elde edilen sonuçların $\mathrm{R}^{2}$ değerlerinin karşılaştırılmasıyla 2 olarak hesaplanmıştır. Bu değer kullanılarak hesaplanan kinetik ve termodinamik analiz sonuçları Çizelge 2' de verilmiştir. 
Çizelge 2. Coats-Redfern modeli kullanılarak hesaplanan kinetik ve termodinamik analiz sonuçları. Table 2. The results of calculated kinetic and thermodynamic parameters using Coats-Redfern.

\begin{tabular}{lllllll}
\hline $\begin{array}{l}\text { Konsantrasyon } \\
(\mathbf{p p m})\end{array}$ & $\begin{array}{l}\text { Reaksiyon } \\
\text { mertebesi }\end{array}$ & $\begin{array}{l}\mathbf{E} \\
\mathbf{( k J} / \mathbf{m o l})\end{array}$ & $\begin{array}{l}\mathbf{A} \\
\left(\mathbf{d a k}^{-\mathbf{1}}\right)\end{array}$ & $\begin{array}{l}\Delta \mathbf{H}^{\circ} \\
\mathbf{( k J} / \mathbf{m o l})\end{array}$ & $\begin{array}{l}\Delta \mathbf{G}^{\circ} \\
\mathbf{( k J} / \mathbf{m o l})\end{array}$ & $\begin{array}{l}\Delta \mathbf{S}^{\circ} \\
\mathbf{( k J} / \mathbf{m o l} . \mathbf{K})\end{array}$ \\
\hline $\mathbf{0}$ & 2 & 134,5 & $8,01 \times 10^{16}$ & 91,09 & 121,70 & $-0,07$ \\
& 2 & 92,0 & $9,38 \times 10^{10}$ & 59,10 & 127,55 & $-0,16$ \\
\hline
\end{tabular}

Çizelge 2 incelendiğinde, struvitin termal bozunması sırasında gerekli olan aktivasyon enerji değeri süksinik asit varlığında azalmıştır. Struvit kristallerinin termal bozunması için hesaplanan pozitif $\Delta \mathrm{H}^{\circ}$ değerleri struvitin bozunma sürecinin endotermik olduğunu ortaya koymuştur. Ayrıca, hesaplanan positif $\Delta \mathrm{G}^{\circ}$ ve negatif $\Delta \mathrm{S}^{\circ}$ değerleri bu sürecin termodinamik olarak kendiliğinden gerçekleşmeyen, dışarıdan enerjiye ihtiyaç duyan bir proses olduğunu göstermiştir.

\section{SONUÇLAR (CONCLUSIONS)}

Bu çalışmada, dikarboksilik bir asit olan süksinik asidin struvit kristalizasyonuna etkisi incelenmiş ve termal bozunma süreci Coast-Redfern kinetik modeli kullanılarak değerlendirilmiştir. XRD ve FTIR sonuçları, hem saf hem de süksinik asit varlığında elde edilen kristallerin ortorombik yapıya sahip struvit kristalleri olduğunu göstermiştir. Zeta potansiyeli ölçüm sonuçlarına göre struvit kristallerinin yüzey yükleri süksinik asit varlığında daha negatif hale gelmiştir. SEM analizi sonuçları, kristalizasyon ortamında bulunan süksinik asidin kristal morfolojisinde ve boyutunda değişikliklere neden olduğunu göstermiştir. Saf ortamda elde edilen kristallerden farklı olarak daha boşluklu, kompakt, aglomerasyon eğilimi az struvit kristalleri elde edilmiştir. Filtrasyon analiz sonuçları, süksinik asit varlığında struvit kristallerinin filtrasyon hızının arttığını, spesifik kek direnci değerinin düştüğünü göstermiştir. CoatsRedfern kinetik modeli kullanılarak yapılan hesaplamalar sonucunda, struvitin termal bozunma sürecinin endotermik olduğu ve bozunma süreci için gerekli minimum enerji ihtiyacının süksinik asit varlığında azaldığı belirlenmiştir.

\section{SEMBOLLER (SYMBOLS)}

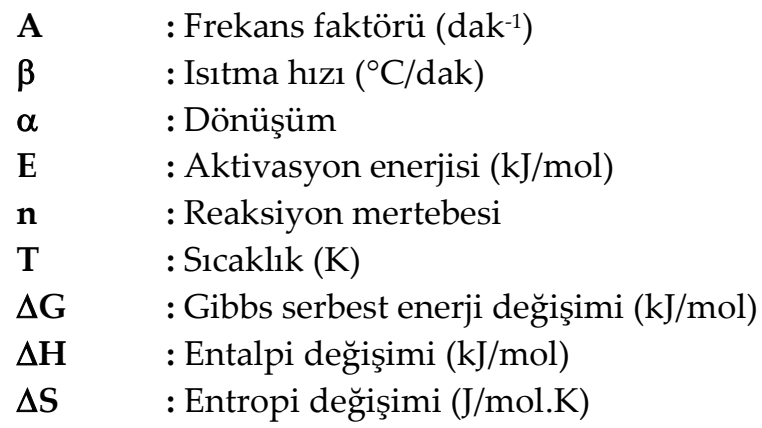

\section{KAYNAKLAR (REFERENCES)}

Akyol, E. Öner M., 2014, “Controlling of morphology and polymorph of calcium oxalate crystals by using polyelectrolytes", Journal of Crystal Growth, 401, 260-265.

Bouropoulos, N.C., Koutsoukos, P.G., 2000, "Spontaneous precipitation of struvite from aqueous solutions", Journal of Crystal Growth, 213(3-4), 381-388.

Coats, A.V., Redfern, J.P., 1964, "Kinetic parameters from thermogravimetric data", Nature, 201, 68-69.

Eyring, H. 1935, "The activated complex in chemical reactions", J. Chem. Phys., 3, 107-115.

Evans, M.G., Polanyi, M., 1935, "Some applications of the transition state method to the calculation of 
reaction velocities, especially in solution", J. Chem. Soc. Faraday Trans., 31, 875-894.

Fattah, K.P, 2012, "Assessing Struvite Formation Potential at Wastewater Treatment Plants", International Journal of Environmental Science and Development, 3(6), 548-552.

Foletto, E.L., dos Santos, W.R.B., Mazutti, M.A., Jahn, S.L., Gündel, A., 2013, “Production of struvite from beverage waste as phosphorous source", Mat. Res., 16, 242-245

Harrison, M.L.L., Johns, M.L.R., White, E.D.T., Mehta, C.G.M., 2011, “Growth rate kinetics for struvite crystallisation", Chemical Engineering Transactions, 25, 309-314.

Holdich, R.G., 1990, "Rotary Vacuum Filter Scale-up Calculations - and the use of Computer Spreadsheets", Filtration \& Seperation, 27(6), 435-439.

Le Corre, K.S., Valsami-Jones, E., Hobbs, P., Jefferson, B., Parsons, S.A., 2007, “Agglomeration of struvite crystals", Water Research, 41(2), 419-425.

Le Corre, K.S., Valsami-Jones, E., Hobbs, P., Parsons, S.A., 2005, "Impact of calcium on struvite crystal size, shape and purity", Journal of Crystal Growth, 283, 514-522.

Neethling, J. B., Benisch, M. 2004, "Struvite control through process and facility design as well as operation strategy", Water Science and Technology, 49(2), 191-199.

Perwitasari, D.S., Edahwati, L., Sutiyono, S., Muryanto, S., Jamari, J., Bayuseno, A.P., 2017, "Phosphate recovery through struvite-family crystals precipitated in the presence of citric acid: mineralogical phase and morphology evaluation", Environmental Technology, 38(22), 2844-2855.

Polat, S., Görener, S., Sayan, P., 2021, "Assessment of the effects of acetic, oxalic, and tricarballylic acids on struvite crystallization: characterisation and kinetic studies", Indian Chemical Engineer, 63(3), 324-337.

Song, Y., Dai, Y., Hu, Q., Yu, X., Qian, F., 2014, “Effects of three kinds of organic acids on phosphorus recovery by magnesium ammonium phosphate (MAP) crystallization from synthetic swine wastewater", Chemosphere, 101, 41-48.

Tansel, B., Lunn, G., Monje, O., 2018, "Struvite formation and decomposition characteristics for ammonia and phosphorus recovery: A review of magnesium-ammonia-phosphate interactions", Chemosphere, 194, 504-514.

Wada, N., Kanamura, K., Umegaki, T., 2001, "Effects of carboxylic acids on the crystallization of calcium carbonate", Journal of Colloid and Interface Science, 233(1), 65-72.

Wei, L., Hong, T., Li, X., Li, M., Zhang, Q., \& Chen, T., 2019, “New insights into the adsorption behavior and mechanism of alginic acid onto struvite crystals", Chemical Engineering Journal, 358, 1074-1082.

Yan, H., Shih, K., 2016, "Effects of calcium and ferric ions on struvite precipitation: A new assessment based on quantitative X-ray diffraction analysis", Water Research, 95, 310-318.

Zhang, Q., Zhao, S., Ye, X., Xiao, W., 2016, "Effects of organic substances on struvite crystallization and recovery", Desalination and Water Treatment, 57(23), 10924-10933.

Zhou, Z., Hu, D., Ren, W., Zhao, Y., Jiang, L. M., \& Wang, L., 2015, “Effect of humic substances on phosphorus removal by struvite precipitation", Chemosphere, 141, 94-99. 